\title{
Nano-sized Droplets of Self-Emulsifying System for Enhancing Oral Bioavailability of Chemotherapeutic Agent VP-16 in Rats: A Nano Lipid Carrier for BCS Class IV Drugs
}

\author{
Nayab Khalid ${ }^{1-2}$, Muhammad Sarfraz ${ }^{1-3}$, Mosab Arafat ${ }^{3}$, Muhammad Akhtar $^{2-4}$, Raimar Löebenberg ${ }^{1}$ a Nisar-Ur- Rahman ${ }^{2-5}$ \\ ${ }^{\mathbf{1}}$ Faculty of Pharmacy and Pharmaceutical Sciences, University of Alberta, Edmonton, Canada. ${ }^{2}$ Faculty of Pharmacy and \\ Alternative Medicine, The Islamia University of Bahawalpur, Punjab, Pakistan. ${ }^{3}$ College of Pharmacy, Al Ain University of \\ Science and Technology, Al Ain, Abu Dhabi, UAE. ${ }^{4}$ Institute of Pharmaceutical Science, Faculty of Life Sciences and \\ Medicine, King's College London, London, UK. ${ }^{5}$ Faculty of Pharmacy, Margalla Institute of Health Sciences, Rawalpindi, \\ Pakistan.
}

Received, July 26, 2018; Revised, October 9, 2018; Accepted, October 23, 2018; Published, October 23, 2018.

\begin{abstract}
PURPOSE: The purpose of this study was to investigate the ability of a self-nano-emulsifying drug delivery system (SNEDDS) to enhance the oral bioavailability of a BCS class IV drug, etoposide (VP-16). METHOD: A series of SNEDDS formulations with VP-16 were prepared consisting of medium chain triglycerides, polysorbate 80 , diethylene glycol monoethyl ether and propylene glycol monolaurate type-1. Based on an obtained ternary phase diagram, an optimum formulation was selected and characterized in terms of size, zeta potential, loading, morphology and in vitro drug release. The pharmacokinetic parameters and oral bioavailability of VP-16 suspension and VP-16 in SNEDDS was assessed using 30 Male Sprague-Dawley rats and compared with the commercial product $\left(\mathrm{VePesid}^{\circledR}\right)$. RESULTS: Pharmacokinetic data showed that the mean values for $\mathrm{AUC}_{0-\mathrm{t}}$ of VP-16 in SNEDDS was 6.4 fold higher compared to a drug suspension and 2.4-folds higher than VePesid ${ }^{\mathbb{R}}$. Similarly, the mean value for $C_{\max }$ of VP-16 in SNEDDS $(1.13 \pm 0.07 \mu \mathrm{g} / \mathrm{ml} \mu \mathrm{g} . \mathrm{h} / \mathrm{mL})$ was higher than $\mathrm{VePesid}^{\circledR}(0.62 \pm 0.09 \mu \mathrm{g} / \mathrm{mL})$ and drug suspension $(0.13 \pm 0.07 \mu \mathrm{g} / \mathrm{mL})$. CONCLUSION: The SNEDDS formulation was able to enhance the oral bioavailability of the BCS Class IV chemotherapeutic agent VP-16 by increasing the dissolution and absorption of the drug. A good in vitro in vivo correlation was found between the in vitro dissolution and in vivo absorption data of VP-16 SNEDDS preparation. Therefore, SNEDDS formulations might be a very promising approach for BCS Class IV drugs.
\end{abstract}

\section{INTRODUCTION}

Oral drug delivery of chemotherapeutic agents is not a common route of administration compared with the intravenous route (I.V.). A previous study showed that the route of drug administration might have an impact on patient adherence and therapeutic costeffectiveness (1). The development of oral chemotherapeutic dosage form is an ongoing field of research because of its impact on the convenience of administration, adherence and compliance particularly in a palliative setting (2) Development of oral dosage forms containing chemotherapeutic agents is still a growing area (3). However, not all types of chemotherapeutic agents can be taken orally due to the high level of solubility and permeability required for intestinal absorption to achieve sufficient oral bioavailability (4). Drug solubility, partitioning, and permeability are the rate determining steps for the intestinal absorption and eventually drug oral bioavailability as described by the biopharmaceutical drug classification system (BCS) (5).

Etoposide or VP-16 is a semi-synthetic derivative compound that is used in the treatment of many cancer types (6). It is a topoisomerase II enzyme inhibitors and DNA synthesis inhibitors (7). It has a molecular weight of $588.58 \mathrm{~g} / \mathrm{mol}$. Pharmaceutically, VP-16 belongs to BCS Class IV drugs due to its low solubility and poor permeability characteristics $(8,9)$. It has been found to be sparingly soluble in water, slightly soluble in ethanol and very soluble in methanol and chloroform.

Its aqueous solubility was reported as $\mathbf{1 6 7 . 2 5}$ $\mu \mathrm{g} / \mathrm{mL}$, at $37^{\circ} \mathrm{C}$ and a rapid degradation rate was

Corresponding Author: Dr Nisar-ur-Rahman, Faculty of Pharmacy, Margalla Institute of Health Sciences. Rawalpindi, Pakistan. E-mail address: nisar60@yahoo.com 
determined at $\mathrm{pH}$ 1.3. In addition, it has a very low extent of absorption (10.16\%) (10-11). Therefore, VP-16 is available to be administered in multipledose vials with different strengths for injection use only. Other pharmaceutical additives involved are citric acid, benzyl alcohol, modified polysorbate 80 , tween 80, polyethylene glycol 300, and alcohol (12).

Nano-sized delivery systems can be used for the oral delivery of hydrophobic drugs using several approached including lipids-based carrier systems (13). Several successful carrier systems containing BCS Class IV drugs have been developed such as furosemide (14) and naproxen (15) Nano-sized drug delivery systems have shown promising results towards the development and optimization of oral drug delivery such as furosemide nanocrystals (16). Nano-sized particles can improve the solubility of many drugs, which in turn has an effect on improving intestinal absorption (17). Studies verified the ability of nano-sized particles $(<100 \mathrm{~nm})$ to penetrate cancerous cells better than normal cells after being potentially absorbed (18). Additionally, tumor blood vessels are usually incomplete and porous. Therefore, nanoparticles can extravasate from the vascular system to deliver the chemotherapeutic agent into the cancerous tissues (19).

Over the last decade, lipid-based vesicular drug delivery systems have been widely investigated for poorly water-soluble drugs (20). Various lipid-based drug delivery systems have been developed aiming to enhance the oral bioavailability of poorly soluble drugs including suspensions, emulsions, microemulsions and self-nano-emulsifying drug delivery systems (SNEDDS) $(21,22)$. SNEDDS have shown promising results in terms of improving solubility and dissolution profiles of many hydrophobic drugs. As a result, higher intestinal permeability and oral bioavailability can be achieved.

Several successful studies investigating the oral bioavailability enhancement of chemotherapeutic agents using SNEDDS have been reported such as bortezomib (23), paclitaxel (24), 5-fluorouracil (25), cisplatin ifosfamide (26) or using phospholipid complex self-emulsifying drug delivery system (PCSEDDS) for VP-16 (27). To the best of our knowledge, this is the first successful study has been carried out to prepare nano-sized droplet consisting of medium chain triglycerides, polysorbate 80, diethylene glycol monoethyl ether and propylene glycol monolaurate type-I in SNEDDS formulation. Therefore, the aim of this study was to enhance the oral bioavailability of VP-16 using the modified SNEDDS. The enhancement of oral bioavailability and pharmacokinetics (PK) of VP-16 in SNEDDS was assessed in comparison to a suspension and VePesid ${ }^{\circledR} 50 \mathrm{mg}$ capsules using 30 rats.

\section{MATERIALS AND METHODS Materials}

Etoposide (VP-16) was obtained from Tecoland Corporation (CA, USA) whereas VePesid ${ }^{\circledR}$ capsules containing $50 \mathrm{mg}$ VP-16 were obtained from BristolMyers Squibb (New York, USA). Labrafac $\mathrm{CC}^{\circledR}$ or medium chain triglycerides (MCT), diethylene glycol monoethyl ether, Carboxymethyl Cellulose Sodium (CMC-Na), propylene glycol monolaurate type-I, polysorbate $80^{\circledR} \quad$ (polyoxyethylene-20 sorbitan monooleate) were purchased from L.V Lomas Ltd (Ontario, Canada). High-performance liquid chromatography (HPLC) grade of sodium dihydrogen orthophosphate, disodium hydrogen orthophosphate, perchloric acid, hydrochloric acid and sodium hydroxide were purchased from SigmaAldrich (MO, USA). Acetonitrile, chloroform and methanol were obtained from Merck (Darmstadt KGaA, Germany).

\section{VP-16 SNEDDS Formulation}

A series of VP-16 SNEDDS were prepared and developed by varying the percentages of Labrafac $\mathrm{CC}^{\circledR}$ (MCT), polysorbate 80 (PSM-20), diethylene glycol monoethyl ether (DGME), propylene glycol monolaurate type-1 (PGM-type-1). The proportion of PSM-20, DGME, PGM-type-1 was kept at 2:1:1 whereas, the MCT added was varied until four formulations namely F1, F2, F3 and F4 were selected (Table 1). Test formulation of SNEDDS was made consisted of MCT, PSM-20, DGME, and PGM-type1 in the ratio of $10: 45: 22.5: 22.5, \mathrm{w} / \mathrm{w} / \mathrm{w} / \mathrm{w}$ whereas $2 \%, \mathrm{w} / \mathrm{v}$ of VP-16 was added. The formulations were prepared by adding first the required amount of drug in an oily vehicle (MCT) at $50^{\circ} \mathrm{C}$. Then, PSM-20 (surfactants), DGME (co-surfactants), and PGMtype-1 (solubilizers) were added in descending order into the glass vial with continuous stirring at $50^{\circ} \mathrm{C}$ for $40 \mathrm{~min}$ until the homogenous SNEDDS were formed. The proportion of surfactant to co-surfactant to solubilize was kept at 2:1:1. The composition of VP-16-SNEDDS formulation of F1, F2, F3 and F4 are shown in Table 1. Fresh samples were used for characterization, drug release studies and in vivo assessment. In addition, a ternary phase diagram was 
developed, and optimum formulation was selected based on the ratio of oil: surfactant: cosurfactant/solubilizer. All samples were subjected to 100 times dilution with distilled water and globule sizes were determined using Zetasizer Nano-DTS 1060 (Malvern Instruments Ltd., UK). Only globules with size less than $100 \mathrm{~nm}$ were highlighted and considered as SNEDDS (figure 2).

\section{In vitro drug release}

In vitro release profiles of three different preparations containing $50 \mathrm{mg} \mathrm{VP}-16$ in the form of 1-drug suspension, 2- SNEDDS formulation, and 3the commercial product of $\mathrm{VePesid}^{\mathbb{B}}$ were evaluated using a modified dissolution method (28). Samples were applied into an enclosed cylinder covered with semipermeable dialysis membrane with membrane molecular weight cut-off (MWCO) of about 12-14 $\mathrm{kDa}$ (Spectrum Laboratories, Rancho Domi, guez, CA, USA). The stirring speed was fixed at $100 \pm 2$ $\mathrm{rpm}$ and temperature at $37 \pm 0.5^{\circ} .150 \mathrm{~mL}$ of simulated intestinal fluid under fast condition (FaSSIF) media which prepared as described in the literature (29) was used and media $\mathrm{pH}$ value was maintained at $\mathrm{pH}$ 6.5. After sink condition was maintained, $1 \mathrm{~mL}$ of sample was taken at various time intervals $(0,10,20,30,40,50$, and $60 \mathrm{~min})$ and replaced with fresh medium to keep the total volume constant at $150 \mathrm{~mL}$. The sample was diluted and measured at a wavelength of $283 \mathrm{~nm}$ using a HPLC system (Agilent Technologies series 1100, USA). Besides, various kinetics models were used namely: First order, Zero order, Higuchi, and Korsmeyer-
Peppas model, to find out the release kinetics and mechanism of drug release.

\section{Globule size, zeta potential, polydispersity index} and drug loading

The globule size, zeta potential (ZP) and polydispersity index (PDI) of SNEDDS loaded VP16 were evaluated using Zetasizer Nano-DTS 1060 (Malvern Instruments Ltd., UK). The instrumental temperature was maintained at $25^{\circ} \mathrm{C}$ and samples were measured at a fixed scattering angle of $173^{\circ}$. The SNEDDS formulation was diluted prior to measurements. SNEDDS were re-suspended and diluted to the appropriate concentration. Half of the fraction of the filtrate was diluted and analyzed immediately for the supernatant containing free drug after dilution using the HPLC method. Triton-X 100 $(1 \%, w / w)$ was added in the ratio of $1: 3$ to release the loaded drug. Prior to analysis, the sample was separated using ultracentrifugation for $5 \mathrm{~min}$ at $30.000 \mathrm{rpm}$ after vortexing for $45 \mathrm{~s}$. The total drug loading (DL) was determined using equation 1.

\section{Transmission Electron Microscopy}

The Transmission Electron Microscope (TEM) images of SNEDDS preparation with and without VP-16 were taken using Philips /FEI (Morgagni) TEM operated with Gatan Digital Camera 23. Samples were prepared by diluting it. Diluted samples were then deposited onto a copper-based grid. The surplus water was removed, and the sample was stained using $2 \%$ phosphotungstic acid solution. Later, the surplus was removed, and the sample was ready for examination.

$$
\text { Drug Loading }(\%, w / w)=\frac{\text { Concentration of drug entrapped in SNEDDS }}{\text { Total concentration of drug and lipids in SNEDDS }} \times 100 \quad \text { Equation (1) }
$$

Table 1. Nano-globule sizes, PDI, ZP and DL of SNEDDS of various oil concentration (data are mean \pm S.D., $n=3$ ).

\begin{tabular}{lllllll}
\hline $\begin{array}{l}\text { SNEDDS } \\
\text { Formulations }\end{array}$ & $\begin{array}{l}\text { MCT } \\
\text { contents } \\
\text { (\%) }\end{array}$ & $\begin{array}{l}\text { Other } \\
\text { composition } \\
\text { (parts) }\end{array}$ & $\begin{array}{l}\text { Globule } \\
\text { size } \\
(\mathbf{n m})\end{array}$ & $\begin{array}{l}\text { Polydispersity } \\
\text { Index } \\
\text { (PDI) }\end{array}$ & $\begin{array}{l}\text { Zeta potential } \\
\text { (ZP) } \\
(\mathbf{m V})\end{array}$ & $\begin{array}{l}\text { Drug loading } \\
\text { (DL) } \\
(\mathbf{\%})\end{array}$ \\
\hline F0 & 0 & $2: 1: 1$ & $15.35 \pm 0.01$ & $0.254 \pm 0.01$ & $-2.43 \pm 0.02$ & $6.45 \pm 0.045$ \\
F1 & 10 & $2: 1: 1$ & $15.89 \pm 0.21$ & $0.11 \pm 0.01^{*}$ & $-5.9 \pm 0.03^{*}$ & $5.35 \pm 0.04$ \\
F2 & 15 & $2: 1: 1$ & $30.99 \pm 0.01^{*}$ & $0.212 \pm 0.02$ & $-6.6 \pm 0.02^{*}$ & $5.65 \pm 0.03$ \\
F3 & 20 & $2: 1: 1$ & $45.68 \pm 1.68^{*}$ & $0.256 \pm 0.01$ & $-12.92 \pm 0.08^{*}$ & $5.83 \pm 0.03$ \\
\hline$* p<0.05$ vs 0\% oil content & & & & \\
\hline
\end{tabular}



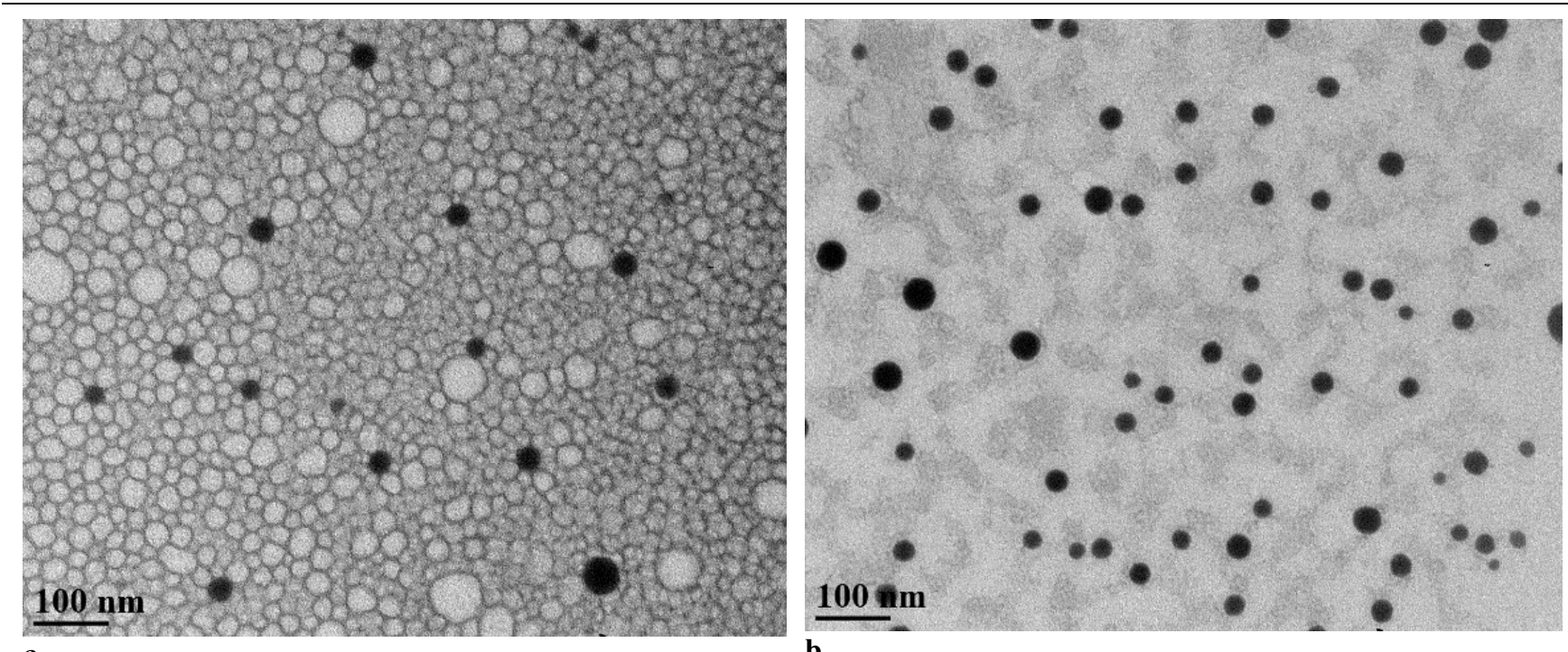

a

b

Figure 2 TEM images of SNEDDS with VP-16 (a) and without VP-16 (b) in distilled water after 1:100 dilutions (black dots representing SNEDDS droplets). Calliper indicates $100 \mathrm{~nm}$. Images were obtained by TEM under X 15,000 magnifications operating at $80 \mathrm{kV}$.

\section{Rat treatment}

30 male Sprague-Dawley rats (age 2-3 months, weight $289 \pm 5.1 \mathrm{~g}$ ) were maintained under simulated natural habitat at $23 \pm 1{ }^{\circ} \mathrm{C}, 12 \mathrm{~h}$ light/dark cycles, and given standard diet and water ad libitum. The rats were allowed to acclimatize before the pharmacokinetic studies for $48 \mathrm{~h}$. Before treatment, the rats fasted overnight until approximately $4 \mathrm{~h}$ post-dose. After dosing, the rats were individually housed in metabolism cages. During blood sampling, rats were kept warm and the cages were covered to provide protection and security and to minimize isolation stress. Immediately after the last blood sample, rats were sacrificed by $\mathrm{CO}_{2}$ asphyxiation.

\section{Pharmacokinetic study}

The study was approved by Pharmacy Research Ethics Committee (ref no 77-2014-PREC) Department of Pharmacy, Faculty of Pharmacy and Alternative medicine, The Islamia University of Bahawalpur, Pakistan. 30 male Sprague-Dawley rats (weight 210-240 g) were used in the experiment. Rats were divided into 3 groups of 10 rats each. In the first phase of sampling: group-1 received a single dose of VePesid ${ }^{\circledR}(2 \mathrm{mg} / \mathrm{kg})$ in PBS solution using oral gavage, group-2 received a single dose of SNEDDS formulation $(2 \mathrm{mg} / \mathrm{kg})$ in PBS solution using oral gavage, group-3 received a single dose of drug suspension $(2 \mathrm{mg} / \mathrm{kg})$ in PBS solution using oral gavage. A $3 \mathrm{~mL}$ of water was given to rats following preparation administration for the purpose of spontaneous formation of SNEDDS in GIT. For sampling, $200 \mu \mathrm{L}$ blood samples were withdrawn from rats from retro-orbital plexus of the eyes of rats and the transferred into heparinized tubes at $0,0.25$, $0.5,0.75,1,2,4,6,8$ and $24 \mathrm{~h}$. Samples were centrifuged at $12,000 \mathrm{~g}$ for $15 \mathrm{~min}$. As a result of centrifugation, plasma samples were obtained, collected and stored at $-21^{\circ} \mathrm{C}$ prior to HPLC analysis. After completing sample collections, rats were sacrificed using carbon dioxide asphyxiation.

\section{HPLC determination of VP-16}

HPLC system (Agilent Technologies series 1100, USA) was used consisting of a HPLC system with a pump and variable wavelength detector set at 203 $\mathrm{nm}$. A Rheodyne 7125 sample injector together with a $20 \mu \mathrm{L}$ sample loop (Rheodyne, USA) was used. An octadecyl silane (ODS) reversed phase analytical column C18 ( $250 \times 4.6 \mathrm{~mm}, 5 \mu \mathrm{m})$ and guard column $(10 \times 2 \mathrm{~mm}, 5 \mu \mathrm{m})$ was used. The mobile phase was running at a flow rate of $1.0 \mathrm{~mL} / \mathrm{min}$ and consisting of methanol: double distilled water $(1: 1, \mathrm{v} / \mathrm{v})$ adjusted to $\mathrm{pH} 4.2$ using $0.2 \mathrm{~N} \mathrm{HCl}$. Chromatographic data was processed by computerized integration software HP Chem Station. All samples were quantified using peak area.

For sample preparation, VP-16 molecules were extracted from blood samples using a number of previously reported methods $(28,30)$. Briefly: an 
aliquot of plasma $(200 \mu \mathrm{L})$ was deproteinized using $200 \mu \mathrm{L}$ aliquots of $4 \%(\mathrm{w} / \mathrm{w})$ perchloric acid. $400 \mu \mathrm{L}$ of treated samples were centrifuged (Eppendorf, Barkhausenweg, Germany) at 12,000 rpm for 15 min. As a result of centrifugation, $20 \mu \mathrm{L}$ of the clear sample was added into $80 \mu \mathrm{L}$ of methanol. $100 \mu \mathrm{L}$ of the final resultant treated sample was analyzed using HPLC system.

A standard curve was prepared to determine VP16 plasma concentration in rats. It was linear over a concentration ration of $0.025-5 \mu \mathrm{g}$, and the correlation coefficient was found to be 0.9997 . The blank sample was clean and free of endogenous adjacent compounds. The total run-time for each sample was $10 \mathrm{~min} .4 \%$ perchloric acid was used as a deproteinizing agent during sample preparation to obtain a satisfactory recovery (31). LOD was 0.015 $\mu \mathrm{g} / \mathrm{mL}$ whereas LOQ was $0.04 \mu \mathrm{g} / \mathrm{mL}$ and at this concentration, intra- and inter-day C.V. were found to be 6.1 and $9.8 \%$, respectively. VP-16 was found to be stable in rat plasma after storage at $-80^{\circ} \mathrm{C}$ for up to 90 days. The current validated HPLC method was used for the analysis of the in vivo PK studies of VP16.

\section{DATA ANALYSIS}

All PK parameters were determined as reported previously (29). All data were expressed as mean \pm SD. A non-compartmental method of analysis was utilized using MS Excel ${ }^{\circledR}$ (Microsoft Corporation 2007) and Kinetica ${ }^{\circledR}$ (Thermo Electron Corporation. An in vitro-in vivo correlation (IVIVC) was established by plotting fraction dose absorbed in vivo versus fraction dose dissolved in vitro. The release kinetics was determined by curve fitting (30).

\section{STATISTICAL ANALYSIS}

All statistical analyses were performed using oneway analysis of variance to compare mean values of each variable for statistical analysis purposes in which $p<0.05$ was considered statistically significant at alpha 0.5 .

\section{RESULTS}

\section{Development of phase diagram}

The optimum SNEDDS formulations area was highlighted in ternary phase diagram within the range from F1 - F3. More than $20 \%$ of oily vehicle mixture was towards the non-SNEDDS area.
Therefore, SNEDDS formulation was prepared using PSM (20), PGM type-I, DGME in a ratio of $(2: 1: 1)$. Based on that different mixtures of SNEDDS were prepared (figure 1). Formulations F1-F3 showed transparency and were selected for further investigations.

\section{Transmission electron microscope (TEM)}

TEM images of SNEDDS with and without VP-16 are shown in figure 2. The formation of SNEDDS containing VP-16 was confirmed by TEM images. It can be seen that the morphological characteristics of SNEDDS in terms of shape were found to be round shape like whereas the appearance of globules with smooth surface surrounded by the ring is representing the SNEDDS with VP-16. On the other hand, characteristics of SNEDDS in terms of droplet sizes were found to be in nano-scale level as the average globule sizes were found to be in the range of 15.35 to $45.68 \mathrm{~nm}$.

\section{Drug loading, globule size, zeta potential and polydispersity index}

Table 1 shows the effect of oil concentration on SNEDDS characteristics in terms of DL, PDI, ZP and droplet sizes. DL for all SNEDDS preparations was found to be within the range of 5.35 and $6.45 \%$ $\mathrm{w} / \mathrm{v}$. The droplet sizes in all SNEDDS preparations were increased from 15.89 to $45.68 \mathrm{~nm}$ as the subsequent oil percentage in the emulsion preparation were increased gradually from 10 to $20 \%$. PDI was found to be within the range of 0.11 to 0.25 . All formulations were found to have PDI value less than 0.25 , which indicates homogeneity and size uniformity of the preparation. On the other hand, ZP of SNEDDS formulations was found to be within the negative charge range from -2.43 to -12.9 $\mathrm{mV}$. The negativity of ZP gradually increased upon increasing the oil percentage in the emulsion preparation.

\section{In vitro Evaluation}

The in vitro dissolution profiles of SNEDDS containing VP-16 (test formulation) and VePesid ${ }^{\circledR}$ (commercial product) and a drug suspension (reference) was measured in FaSSIF media at pH 6.5 is shown in figure 3 . It can be seen that $90 \%$ of the drug in the test formulation was released within 90 min, whereas only up to 50 and $7 \%$ of the drug was released for the commercial product and drug suspension, respectively. The dissolution rate of SNEDDS contained VP-16 was significantly faster 
and higher $(p<0.05)$ than that of VePesid ${ }^{\circledR}$ and a drug suspension.

\section{In vivo assessment and in vivo-in vitro correlation} Mean plasma concentration of VP-16 in the three formulations after been given orally to a rat is shown in figure 4 . The increase in oral bioavailability using SNEDDS was remarkable as compared to a drug suspension and the commercial product. PK parameters $\left(\mathrm{AUC}_{0-\infty}, \mathrm{C}_{\max }\right.$ and $\left.\mathrm{T}_{\max }\right)$ obtained after oral administration for all preparations are shown in Table 2. It can be seen that the mean $\mathrm{AUC}_{0-\infty}$ value of VP-16 in SNEDDS (3.24 $\pm 0.4 \mathrm{~h} . \mu \mathrm{g} / \mathrm{mL})$ was almost 6.4-fold higher than that of the drug suspension $(0.51 \pm 0.1 \mathrm{~h} . \mu \mathrm{g} / \mathrm{mL})$ and 2.5-fold higher than that of $\mathrm{VePesid}^{\circledR}(1.32 \pm 0.35$ h. $\mu \mathrm{g} / \mathrm{mL})$. Significant differences $(p<0.05)$ were observed for $\mathrm{AUC}_{0-\infty}$ between SNEDDS and VePesid ${ }^{\circledR}$ and the suspension.

For $T_{\max }$, the SNEDDS plasma concentration peak was reached at $1.5 \pm 0.12 \mathrm{~h}$, whereas $1.12 \pm$ $0.13 \mathrm{~h}$ for $\mathrm{VePesid}^{\circledR}$ and $2.2 \pm 0.14 \mathrm{~h}$ for the drug suspension. $\mathrm{T}_{\max }$ is a measure of the rate of absorption. The $\mathrm{p}$-value for $\mathrm{T}_{\max }$, of SNEDDS was found to be significantly different $(p<0.05)$ as compared to $\mathrm{VePesid}^{\circledR}$ and the drug suspension. Likewise, $\mathrm{C}_{\max }$ of SNEDDS were found to be 1.13 \pm $0.07 \mu \mathrm{g} / \mathrm{mL}$, whereas $C_{\max }$ for commercial product and the drug suspension, were found to be $0.62 \pm 0.09$ and $0.13 \pm 0.07 \mu \mathrm{g} / \mathrm{mL}$, respectively. The $\mathrm{p}$-value for $\mathrm{C}_{\max }$, of the SNEDDS was found to be significantly higher $(p<0.05)$ as compared to $\mathrm{VePesid}^{\circledR}$ and the drug suspension.

The values for $\mathrm{Ke}, \mathrm{Vd}$ and $\mathrm{t}_{1 / 2}$ are given in Table 2. The Ke of SNEDDS and VePesid ${ }^{\circledR}$ capsules were found to be statistically significantly different $(p=0.0480)$. Similarly, a $p$-value of Vd for SNEDDS and $\mathrm{VePesid}^{\circledR}$ were found to be statistically significantly different $(p=0.0040)$. This might be due to an increase in the $\mathrm{C}_{\max }$ of SNEDDS as the inverse relationship was found to exist between $\mathrm{Vd}$ and $\mathrm{C}_{\max }$. In contrast, the $p$-value for $t \frac{1}{2}$ values of SNEDDS and $\mathrm{VePesid}^{\circledR}$ capsules were found to be statistically significantly different at $95 \%$ confidence interval. Besides, mean residence time (MRT) of SNEDDS, VePesid $^{\circledR}$ capsules and drug suspension were also calculated from the $\mathrm{AUC}_{0-\mathrm{t}}$ and the values were found to be $3.6 \pm 0.7,2.6 \pm 0.4$ and $4.01 \pm 0.6 \mathrm{~h}$ and were statistically significantly different $(p<0.05)$.

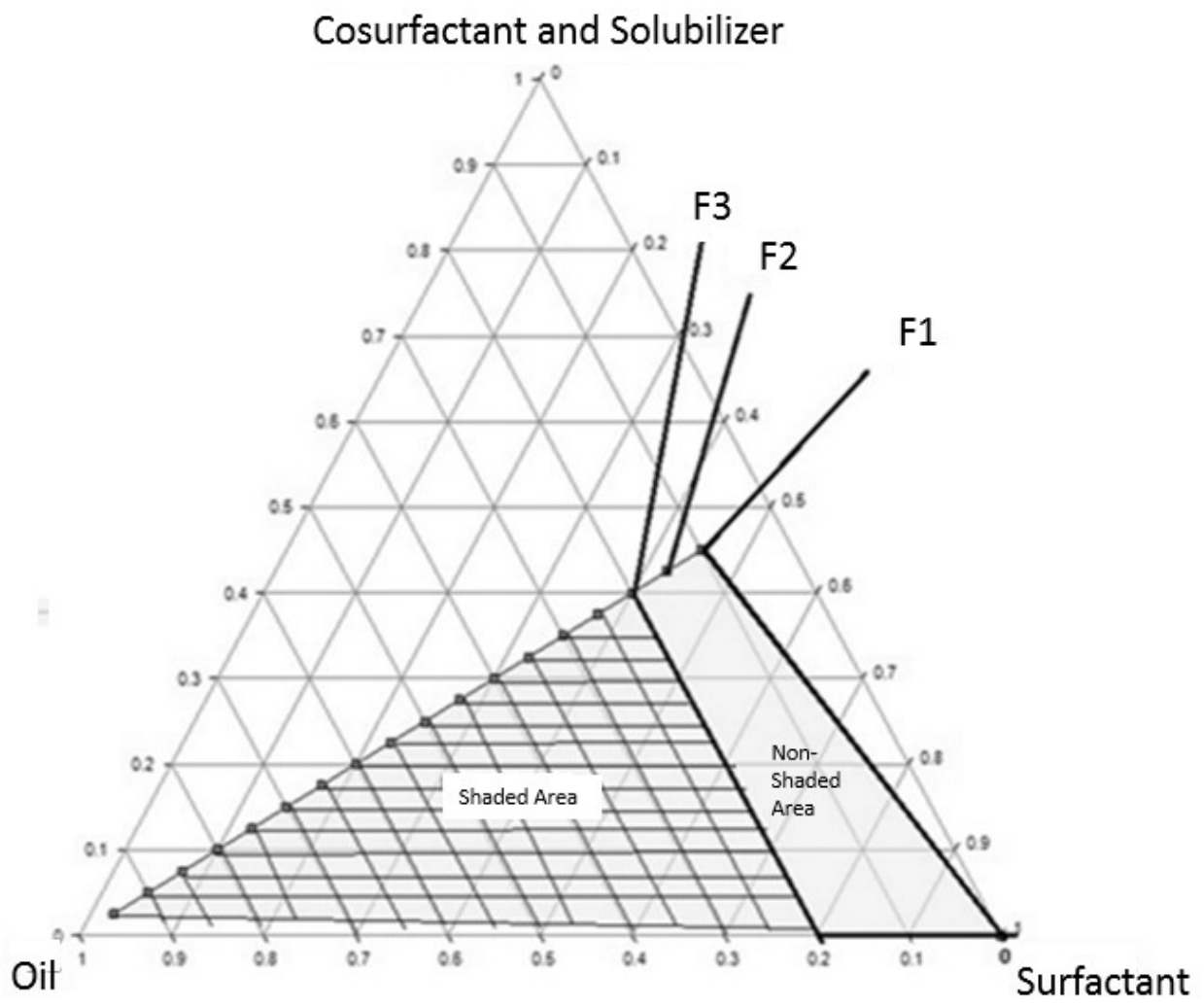

Figure 1 Ternary phase diagram of different percentage of MCT (oily vehicle), PSM 20 (surfactant), PGM type-I (co-surfactant), DGME (Solubilizer) mixtures in 100 fold water. Shaded and non-shaded are shown non-SNEDDS area and SNEDDS area, respectively. 


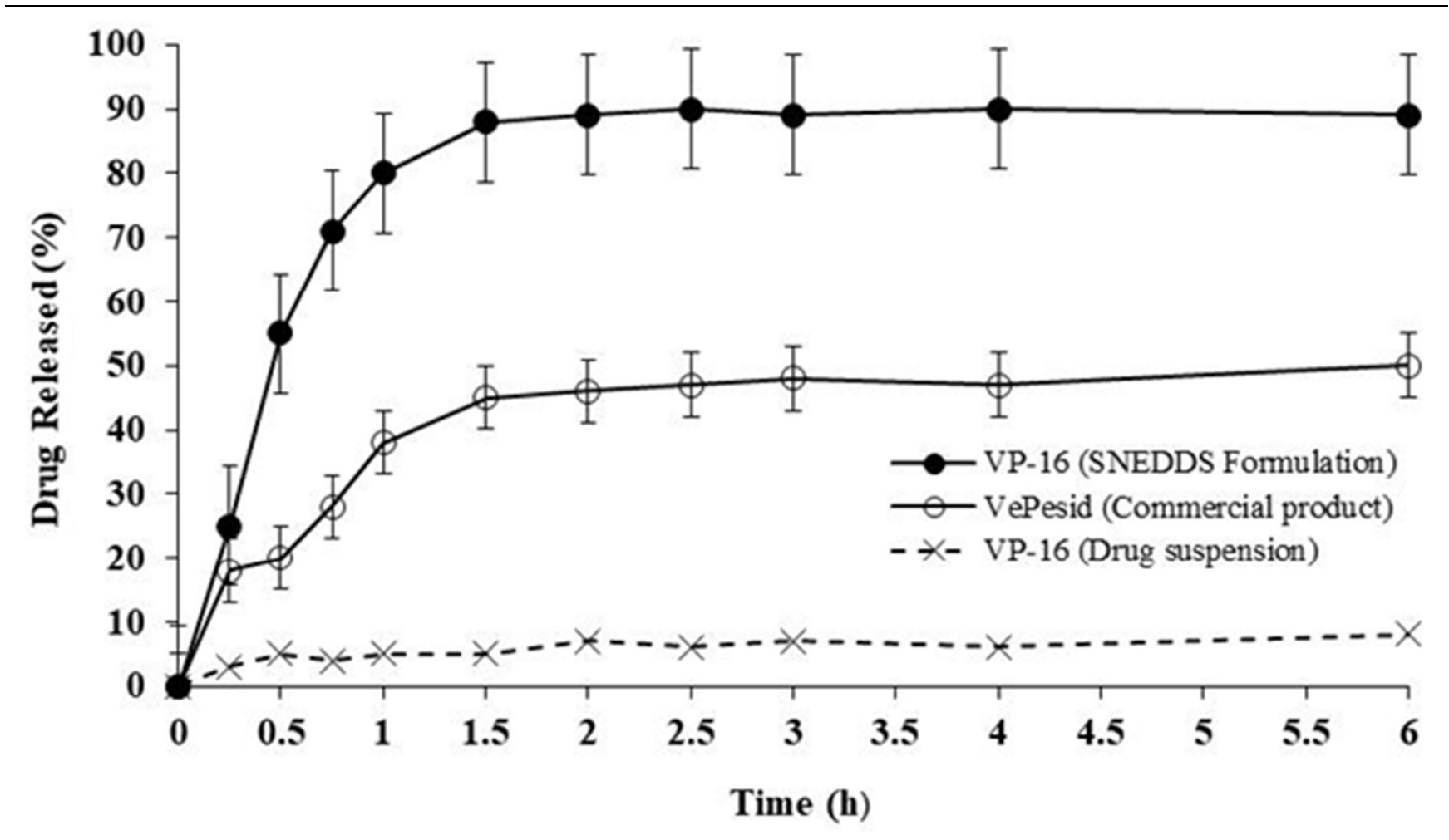

Figure 3 In vitro drug release of VP-16 in SNEDDS formulation, VePesid ${ }^{\circledR}$ and VP-16 suspension at $37^{\circ} \mathrm{C}$, over $24 \mathrm{~h}$ in FaSSIF media at $\mathrm{pH} 6.8$.

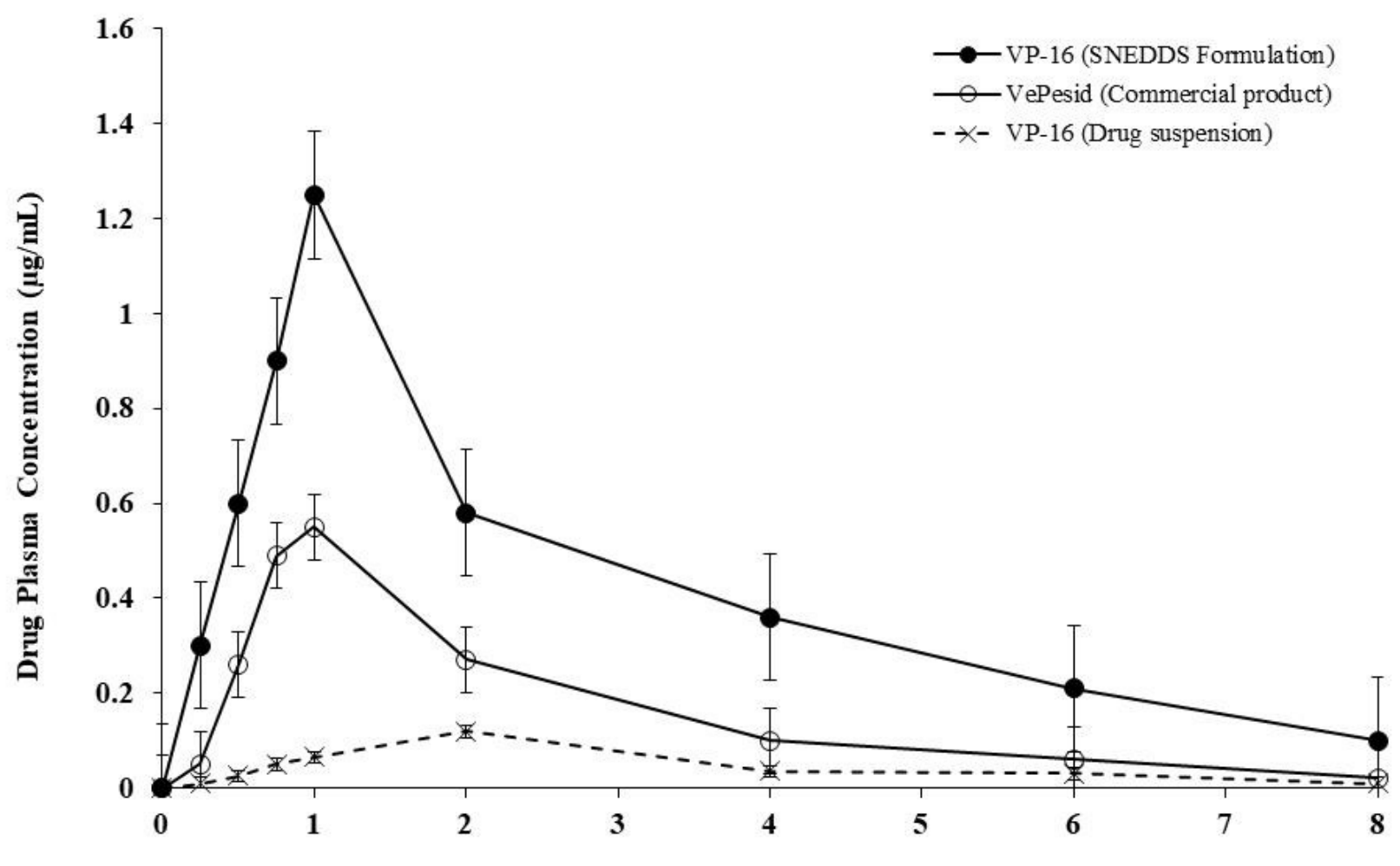

Time (h)

Figure 4 Plasma concentration-time profile of VP-16 after oral administration of VP-16 in SNEDDS Formulation, VePesid ${ }^{\circledR}$ and drug suspension to male Sprague-Dawley rats. Data are presented as mean \pm s.d., $\mathrm{n}=10$. 
Table 2. Pharmacokinetic parameters of VP-16 after oral administration of VP-16 in SNEDDS formulation, VePesid ${ }^{\circledR}$ and drug suspension using 30 rats. Data are presented as mean \pm s.d., $\mathrm{n}=10$.

\begin{tabular}{|c|c|c|c|}
\hline PK & VP-16 (suspension) & VePsid (commercial) & VP-16 (SNEDDS) \\
\hline Weight & $219.51 \pm 19.3$ & $229.56 \pm 25.4$ & $212.11 \pm 9.38$ \\
\hline $\mathrm{C}_{\max }(\mu \mathrm{g} / \mathrm{ml})$ & $0.13 \pm 0.08$ & $0.62 \pm 0.09$ & $1.13 \pm 0.06^{*}$ \\
\hline $\mathrm{T}_{\max }(\mathrm{h})$ & $2.0 \pm 0.14$ & $1.12 \pm 0.13$ & $1.50 \pm 0.12 *$ \\
\hline $\mathrm{AUC}_{0-\infty}(\mathrm{hr} . \mu \mathrm{g} / \mathrm{ml})$ & $0.51 \pm 0.23$ & $1.32 \pm 0.35$ & $3.24 \pm 0.36^{*}$ \\
\hline $\mathrm{Vd}(\mathrm{L})$ & $1521.8 \pm 36.5$ & $948.24 \pm 36.5$ & $512.71 \pm 37.9^{*}$ \\
\hline$t_{1 / 2}(h)$ & $3.17 \pm 0.48$ & $1.66 \pm 0.48$ & $2.37 \pm 0.69 *$ \\
\hline $\mathrm{K}_{\mathrm{e}}\left(\mathrm{hr}^{-1}\right)$ & $0.52 \pm 0.14$ & $0.44 \pm 0.11$ & $0.32 \pm 0.11 *$ \\
\hline
\end{tabular}

Figure 5 shows the relationship between the in vivo absorption times versus the in vitro dissolution times of VP-16 (SNEDDS Formulation) and VePesid ${ }^{\circledR}$ (VP-16 commercial product). The VP-16 (SNEDDS Formulation) plot showed a linear relationship while the VePesid ${ }^{\circledR}$ (VP-16 commercial product) showed the best fit to a first order release pattern. This was attributed to the differences in the absorption rate of the two products. The commercial product exhibited a typical immediate release in vitro dissolution behaviour and no IVIVC is expected because absorption occurs much slower. For the SNEDDS Formulation, the in vitro drug release was controlled by the formulation and the in vivo absorption rate followed the drug release pattern. Therefore, a good IVIVC was observed for SNEDDS preparations with a correlation coefficient value of 0.980 .

\section{DISCUSSION}

Based on ternary phase diagram (figure 1), formulations F1-F3 were considered as an optimum formulations, because they showed an emulsion system having a nano-sized droplet with less than $100 \mathrm{~nm}$, therefore they were selected for further investigation whereas F1 was selected as the best formulation due to the optimum dissolution profile was obtained. TEM images (figure 2) show the formation of a thick layer surrounding each nanodroplet in the formulation suggested that the oil dissolved in the bulk is (partly) consumed by the growing surface droplets, leading to the dropletdepleted area in the surrounding region. This might reduce the interfacial tension energy and is forming a physical barrier to prevent droplet coalescence. The obtained droplet sizes in the TEM images (15.56 to $45.23 \mathrm{~nm}$ ) were found to be in good agreement with droplet size distribution obtained by photon correlation spectroscopy (Table 1) (28,31). Besides, low polydispersity index values obtained for all formulations, indicating a narrow droplet size distribution and suggesting a uniformity of the droplet size distribution. The slight increasing in negative charge values found for the SNEDDS formulations could be attributed to the involvement of an anionic groups of fatty acids and glycols present in the formulation. Thus, further repulsion between droplets due to the negative charge could contribute to prevent droplet flocculation in the dispersion medium and hence enhance the physical stability of the emulsion system (32).

In terms of in vitro drug release profile (figure 3 ), the result shows that the drug release of VP-16 from SNEDDS formulations (2\%, w/v of VP-16) consisted of MCT, PSM-20, DGME, and PGM-type1 in the ratio of $10: 45: 22.5: 22.5, \mathrm{w} / \mathrm{w} / \mathrm{w} / \mathrm{w}$ was able to reach up to $90 \%$ of VP-16 release over $90 \mathrm{~min}$. The release kinetics were fitted to a first-order kinetics after been tested with several kinetics models (33). The significant increase of drug release profile $(p<0.05)$ as compared to that of a drug suspension and commercial product indicated that SNEDDS have the capability to increase drug solubility remarkably which resulted in an enhancement of in vitro drug release. Similar results were reported for anti-tuberculosis drugs (34).

It is suggested that SNEDDS dispersion form an emulsion, as a result of this emulsion formation, molecules tend to dissolve readily in the oil phase and get transported through the dialysis membrane. The oral bioavailability enhancement of VP-16 in the SNEDDS formulation is an indication of better solubility and higher absorption rate of the drug. This could occur due to improved solubilization of drug in the lipophilic vesicles which resulted in a better interaction with the intestinal membrane. 


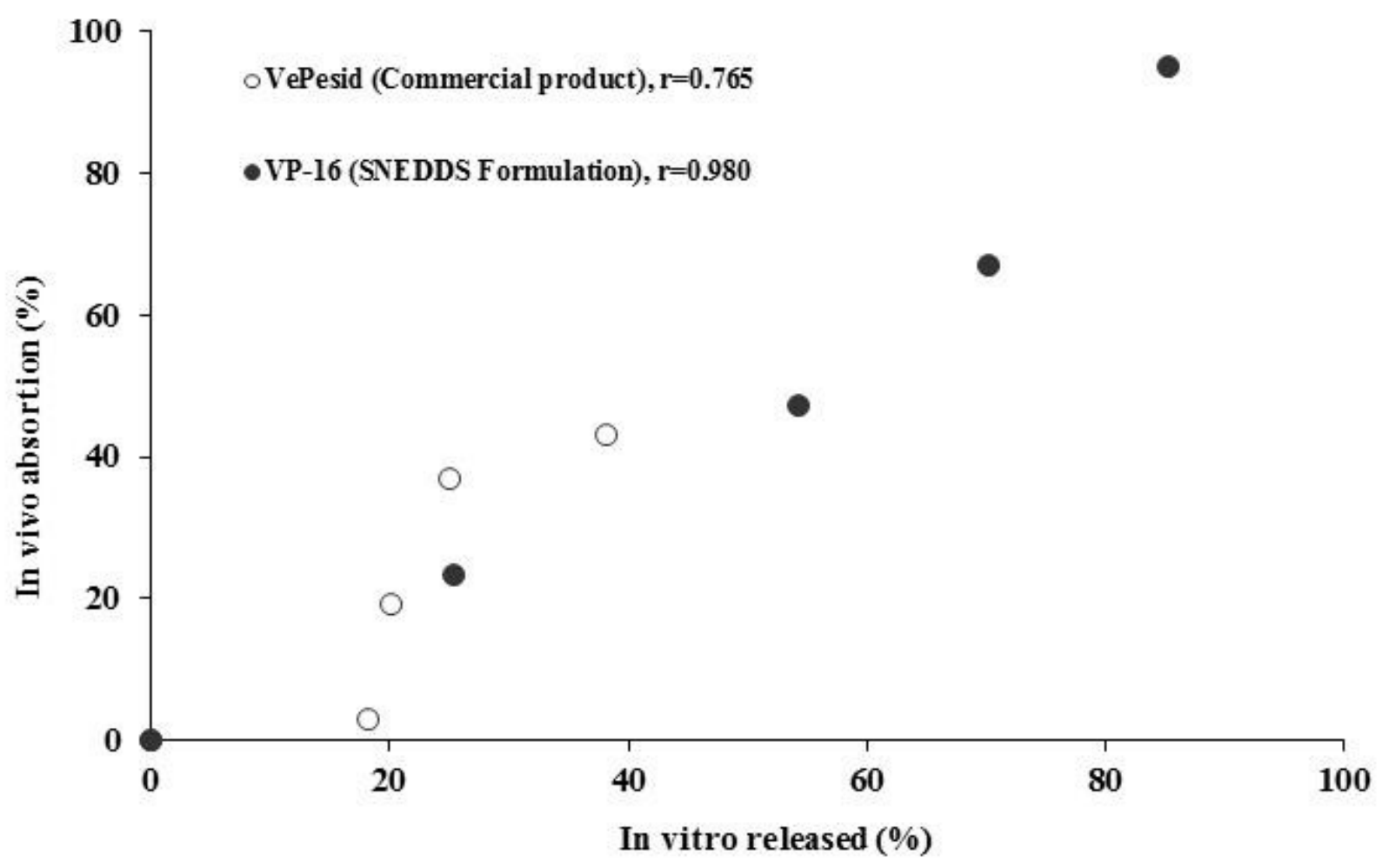

Figure 5. In vivo VP-16 absorption versus in vitro VP-16 released profile for VP-16 (SNEDDS) and VePesid ${ }^{\circledR}$ (VP-16 commercial product).

The presence of MCT as oil vehicle could strengthen the affinity with the cell membrane. Another possibility of oral bioavailability enhancement is due to mixed micelles formation (35-36). Besides, the involvement of surfactant in the emulsion could play an essential role in decreasing the interfacial surface tension and increasing the interfacial surface area due to the small emulsion droplets which in turn could enhance the integration with epithelial cells and hence, increase drug absorption $(36,37)$.

The current findings showed a significant increase in the oral bioavailability of VP-16 using SNEDDS (6.4-fold) which is higher than that reported previously (2.5 fold) but with using microemulsions system (27). This increases in the oral bioavailability of VP-16 using SNEDDS could be attribute to the presence of polysorbate 80 in the emulsion composition. Previous studies reported that when polysorbate 80 interacted with efflux pumps, drug bioavailability can be enhanced by causing inhibition of drug mediated efflux transporters of Pglycoprotein $(38,39)$ to which VP-16 is a substrate (40).

\section{CONCLUSION}

In conclusion, SNEDDS were found to be able to enhance the oral bioavailability of the BCS class IV drug, VP-16 up to 6.4-fold as compared to the drug suspension and 2.5 -fold as compared to commercial product VePesid ${ }^{\circledR}$. The in vitro drug release studies showed that the dissolution release profile of VP-16 from SNEDDS formulation was faster and higher than that of a drug suspension and commercial product. The addition of MCT and polysorbate 80 to the SNEDDS might have an essential effect in enhancing the oral bioavailability of VP-16. Besides, a good IVIVC was found between the in vitro dissolution and in vivo absorption data of VP16 SNEDDS preparation. Therefore, the SNEDDS system may represent a promising oral drug delivery system for BCS class IV drug like VP-16.

\section{COMPLIANCE WITH ETHICAL STANDARDS}

\section{Conflict of interest}

The authors declare that they have no conflicts of interest to disclose. 


\section{Ethical Approval}

All procedures used in the present study were conducted in accordance with the guidelines approved by the Pharmacy Research Ethics Committee (ref no 77-2014-PREC) Department of Pharmacy, Faculty of Pharmacy and Alternative medicine.

\section{ACKNOWLEDGMENT}

The authors are grateful and thankful to the Faculty of Pharmacy and Pharmaceutical Sciences at the University of Alberta, Canada for having the great opportunity to conduct part of this study and analysis at their laboratories.

\section{REFERENCES}

1. Mazzaferro S, Bouchemal K, Ponchel G. Oral delivery of anticancer drugs I: general considerations. Drug Discov Today. 2013;18: 25-34.

2. Liu G, Franssen E, Fitch M, Warner E. Patient preferences for oral versus intravenous palliative chemotherapy. J Clin Oncol.1997;15:110-115.

3. O'Neill VJ, Twelves CJ. Oral cancer treatment: developments in chemotherapy and beyond. $\mathrm{Br} \mathrm{J}$ Cancer. 2002;87:933-937.

4. Arafat M. The effect of intestinal bile on the stability of lipid-based vesicular system used as oral drug carriers. Glob Drugs Ther.2016; 2:1-2.

5. Löbenberg $\mathrm{R}$ and Amidon G.L. Modern bioavailability, bioequivalence and biopharmaceutics classification system. New scientific approaches to international regulatory standards. Eur. J. Pharm. Biopharm.2000;50:3-12.

6. Shirazi FH, Bahrami G, Stewart DJ, Tomiak E, Delorme F, Noel D, Goel R. A rapid reversed phase high performance liquid chromatographic method for determination of etoposide (VP-16) in human plasma. J Pharm Biomed Anal. 2001; 25:353-356.

7. Burden DA, Kingma PS, Froelich-Ammon SJ, Bjornsti MA, Patchan MW, Thompson RB, Osheroff N. Topoisomerase II. Etoposide interactions direct the formation of drug-induced enzyme-DNA cleavage complexes. J Biol Chem.1996;271:2923844.

8. KhadkaaP, RoaJ, Kim H, Kim I, Kim JT, Kim H, Cho JM, Yun G, Lee J. Pharmaceutical particle technologies: An approach to improve drug solubility, dissolution and bioavailability. As J Pharm Sci.2014;9:304-3168.

9. Custodio JM, Wu CY, Benet LZ. Predicting drug disposition, absorption/elimination/transporter interplay and the role of food on drug absorption. Adv Drug Deliv Rev.2008;60:717-733.
10. Shaha JC, Chen JR, Chowa D. Oral bioavailability and in situ absorption of etoposide in rat. Int $\mathbf{J}$ Pharm.1992; 84;20:223-232.

11. Wu Z, Guo D, Deng L, Zhang Y, Yang Q, Chen J. Preparation and evaluation of a self-emulsifying drug delivery system of etoposide-phospholipid complex. Drug Dev Ind Pharm. 2011;37:103-112.

12. Jain J, Fernandes C, Patravale V. Formulation Development of Parenteral Phospholipid-based Microemulsion of Etoposide. AAPS Pharm Sci Tech.2010;11:826-831.

13. Sandeep-Kalepu, Manthina M, Padavala V. Oral lipid-based drug delivery systems - an overview. Acta Pharm Sin B. 2013; 3: 361-372.

14. Sambaraj S, Ammula D, Nagabandi V. Furosemide Loaded Silica-Lipid Hybrid Microparticles: Formulation Development, in vitro and ex vivo Evaluation. Adv Pharm Bull. 2015; 5: 403-409.

15. Bhoyar PK, Morani DO, Biyani DM, Umekar MJ, Mahure JG, Amgaonkar YM. Encapsulation of Naproxen in Lipid-Based Matrix Microspheres: Characterization and Release Kinetics. J Young Pharm.2011; 3: 105-111.

16. Barbosa SF, Takatsuka T, Tavares GD, Araújo GLB, Wang H, Vehring R, Löbenberg R,Bou-Chacra N.A. Physical-chemical properties of furosemide nanocrystals developed using rotation-revolution mixer. Pharm. Dev. Technol. 2016; 21: 812-822.

17. Zhang $\mathrm{P}$, Liu Y, Feng N, Xu H. Preparation and evaluation of self-emulsifying drug delivery system of oridonin. Int J Pharm 2008; 355:269-76.

18. Jabir NR, Tabrez S, Ashraf GM, Shakil S, Damanhouri GA, Kamal MA. Nanotechnology-based approaches in anticancer research. Int $\mathrm{J}$ Nanomedicine. 2012; 7: 4391-4408.

19. Singh AK, Chaurasiya A., Awasthi A, Mishra G, Asati D, Khar RK., Mukherjee R. Oral bioavailability enhancement of exemestane from selfmicroemulsifying drug delivery system (SMEDDS). AAPS Pharm Sci Tech. 2009; 10: 906-916.

20. Pouton CW. Formulation of poorly water-soluble drugs for oral administration: physicochemical and physiological issues and the lipid formulation classification system. Eur J Pharm Sci.2006;29:27887.

21. Pouton CW. Lipid formulations for oral administration of drugs: nonemulsifying, selfemulsifying and 'self-microemulsifying' drug delivery systems. Eur J Pharm Sci.2000;11 (Suppl. 2) S93-8.

22. Hauss DJ, Fogal SE, Ficorilli JV, Price CA, Roy T, Jayaraj AA, et al. Lipid-based delivery systems for improving the bioavailability and lymphatic transport of a poorly water-soluble LTB4 inhibitor. J Pharm Sci.1998;87:164-9.

23. Hong EP, Kim JY, Kim SH, Hwang KM, Park CW, Lee HJ, Kim DW, Weon KY, Jeong SY, Park ES. 
Formulation and Evaluation of a Selfmicroemulsifying Drug Delivery System Containing Bortezomib. Chem Pharm Bull. 2016; 64:1108-1117.

24. Yang S., Gursoy RN, Lambert G, Benita S. Enhanced oral absorption of paclitaxel in a novel selfmicroemulsifying drug delivery system with or without concomitant use of P-glycoprotein inhibitors. Pharm Res. 2004; 21:261-270.

25. Kamal T, Sarfraz M, Arafat M, Mikov M, Rahman N. Cross-linked guar gum and sodium borate based microspheres as colon-targeted anticancer drug delivery systems for 5-fluorouracil. Pak J Pharm Sci.2017; 30 (Suppl.6): 2329-2336.

26. Ujhelyi Z, Kalantari A, Vecsernyés M, Róka E, Fenyvesi F, Póka R, Kozma B, Bácskay I. The enhanced inhibitory effect of different antitumor agents in self-microemulsifying drug delivery systems on human cervical cancer HeLa cells. Molecules.2015; 20:13226-13239.

27. Wu Z, Guo D, Deng L, Zhang Y, Yang Q, Chen J. Preparation and evaluation of a self-emulsifying drug delivery system of etoposide-phospholipid complex. Drug Dev Ind Pharm. 2011;37:103-12.

28. Khalid N, Rahman N, Löbenberg R, Akhtar M, Sarfaraz M, Hajjar M. Design and Evaluation of SMEDDS to Enhance Solubility and Dissolution of Anticancer Drug Using Modified Cylinder Method. Lat Am J Pharm. 2017; 36: 647-57.

29. Arafat M, Kirchhoefer C, Mikov M, Sarfraz M, Löbenberg R. Nanosized liposomes containing bile salt: A vesicular nanocarrier for enhancing oral bioavailability of BCS class III drug. J Pharm Pharm Sci 2017; 20: 305-318.

30. Zuo J, Gao Y, Bou-Chacra N, Löbenberg R. Evaluation of the DDSolver software applications. Biomed Res Int. 2014;2014:204925. doi: 10.1155/2014/204925.

31. Arafat M, Golocorbin-kon S, Mikov M. The measurement of cefotaxime sodium in rat plasma after oral administration: a sensitive HPLC-UV method. Int J Pharm Pharm Sci. 2015; 7: 343-346.

32. Golocorbin-Kon S, Mikov M, Arafat M, Lepojevic Z, Mikov I, Sahman-Zaimovic, $M$ et al. Cefotaxime pharmacokinetics after oral application in the form of 3 alpha,7 alpha-dihydroxy-12-keto-5 betacholanate microvesicles in rat. Eur J Drug Metab Pharmacokinet, 2009; 34: 31-36.
33. Hanbali OA, Hamed R, Arafat M, Bakkour Y, Matubsi H, Mansour R, Bataineh Y, Aldhoun M, Sarfraz M, Dardas Y. Formulation and evaluation of diclofenac controlled release matrix tablets made of HPMC and Poloxamer 188 polymer: An assessment on mechanism of drug release. Pak J Pharm Sci.2018;31 (Suppl.1):345-351.

34. Y. Gao, J. Zuo, N. Bou-Chacra et al., "In vitro release kinetics of anti-tuberculosis drugs from nanoparticles assessed using a modified dissolution apparatus," BioMed Research International,2013; Article ID 136590, 9 pages.

35. Gao, Yuan; Sarfraz, Muhammad Khan; Clas, SophieDorothee; Roa, Wilson; Löbenberg, Raimar.Hyaluronic acid-tocopherol succinate-based self-assembling micelles for targeted delivery of rifampicin to alveolar macrophages Journal of Biomedical Nanotechnology, 2015;11:1312-1329.

36. Arafat M, Kirchhoefer C, Mikov M. Mixed micelles loaded with bile salt: an approach to enhance intestinal transport of the BCS class III drug cefotaxime in rats. Eur J Drug Metab Pharmacokinet.2017; 42:635-645.

37. Venkatesh G, Majid MIA, Mansor SM, Nair NK, Croft SL, Navaratnam V. In vitro and in vivo evaluation of selfmicroemulsifying drug delivery system of buparvaquone. Drug Dev Ind Pharm. 2010; 36:735-745.

38. Sachs-Barrable K, Lee SD, Wasan EK, Thorntona SJ, Wasana KM. Enhancing drug absorption using lipids: A case study presenting the development and pharmacological evaluation of a novel lipid-based oral amphotericin B formulation for the treatment of systemic fungal infections. Adv Drug Deliv Rev. 2008; 60:692-701

39. Li Y, Pan WS, Chen SL, Xu HX, Yang DJ, Chan ASC. (Pharmacokinetic, tissue distribution, and excretion of puerarin and puerarin-phospholipid complex in rats. Drug Dev Ind Pharm. 2006, 32:41322.

40. Tazawa Y, Usukubo I, Takada K, Takekuma Y, Shibayama Y, Sugawara M. Schedule-dependent cytotoxicity of Etoposide and cyclophosphamide in P-glycoprotein-expressing human leukemic K-562 cells. Biol Pharm Bull. 2014; 37: 1323-1329. 